\title{
A new consideration about floating storage and regasification unit for liquid natural gas
}

\author{
${ }^{1}$ Mihai Sagau, ${ }^{1}$ Mariana Panaitescu, ${ }^{1}$ Fanel-Viorel Panaitescu, ${ }^{1}$ Scupi Alexandru-Andrei \\ ${ }^{1}$ Department of Engineering Sciences in Mechanical and Environmental Field \\ Constanta Maritime University \\ Constanta, Romania \\ marianapan@yahoo.com
}

Received: January 30, 2021 Revised: March 1, 2021. Accepted: March 10, 2021. Published: March 24, 2021.

\begin{abstract}
In this paper we want to present the details of new project about floating liquid natural gas (LNG) regasification terminal based on conversion of an existing LNG carrier . LNG is sent from the tanks to the regasification skid fwd. The regasification skid essentially comprises booster pumps and vaporizers This project can boost both transport and economy sector of Central European countries by introducing a less expensive fuel, more environmental friendly and with a good perspective in the future. The project consists in building a LNG import terminal in Constanta, harbor from where the merchandise (LNG in this situation) can easily be delivered on Danube's basin and reach central European countries.
\end{abstract}

Keywords-floating storage; regasification; style; liquid natural gas; process; diagram; modelling flow

\section{INTRODUCTION}

Up to now there was little or none import and use of LNG in countries like: Germany, Austria, Slovakia, Hungary, Serbia, Bulgaria, unlike other European countries that have over 20 years of using LNG. The reason these countries didn't profit from the benefits of LNG usage is that there was little access to import LNG and if there was, it was very expensive. In order to deliver LNG to Austria a railway or truck transport should have been organized in special containers from the LNG terminal near a sea to Austria[1].

Through the terminal built in Constanta specialized vessels could transport LNG at lower prices to all countries upstream Danube. The project is in accordance with EUROPEAN TRANSPORT STRATEGY TEN-T INTEGRATION (AXIS NO. 18) and is built in the context of similar functional LNG terminals in EU: SPAIN (6), FRANCE (3), UNITED KINDOM (3), ITALY (2), PORTUGAL (1), BELGIUM (1), SWEDEN (1), GREECE (1). As we can observe, Constanta LNG terminal is the only one in the Black sea, and except the one in Greece, the only one in Central-Eastern Europe.

The general goal of this project is to extend the energy sources to ones that maintain a cleaner and more sustainable environment, a source of energy that is less voluminous and can be transported in big quantities.

In this paper we present more informations about regasification process[2].

\section{FLOATING STORAGE AND REGASIFICATION UNIT FOR LNG}

\section{A. Technical specifications for the FSRU in LNG import terminal in Constanta-South-Agigea}

FSRU will be placed FSRU will be placed offshore, 4 $[\mathrm{km}]$ from the shore; Storage capacity: $135.000\left[\mathrm{~m}^{3}\right]$; FSRU specifications: Length-289 m; Beam- moulded breadth=48 [m]; Deadweight 82100 [t]; Draft 12.5 [m]; Gross tonnage 115000 [t]; Net tonnage- 34550 [t]; Minimum depth for offshore mooring an FSRU is 15 [m]; Minimum depth for pierside or jetty mooring is $>14[\mathrm{~m}]$; Designed for benign waters-Agigea waters are considered very suitable; Design lifetime: 30 years at location; Regas send-out requirements: minimum rate 50 $[\mathrm{t} / \mathrm{h}]$; maximum rate 250 [t/h; Vaporizers: with propane and sea water; Steam from existing ship boilers used for regas; Fuel consumption 50 [t] LNG per day $/ 100 \%$ regas capacity; DNV class notation: REGAS-1. The FSRU is supplied with LNG by shuttle tankers berthing side by side to it, through 4 loading arms at a flow rate of $8000\left[\mathrm{~m}^{3} / \mathrm{h}\right]$, this means that max $20[\mathrm{~h}]$ are required to download a vessel of $135000\left[\mathrm{~m}^{3}\right]$ capacity at max discharging rate including mooring and de-mooring time. The terminal is designed to perform 3-4 discharging operations/month. The loading lines are kept in refrigerated(cold) condition between 2 dischargings through a small recirculation of $\mathrm{LNG}$ so as to shorten the cool-down phase and therefore reduce the overall duration of unloading operation. The FSRU is equipped with 3 Tri-Ex type units using large quantities of seawater as a heating medium. Operational condition - Limit for LNGC unmooring and loading arm disconnection. Max. Wind speed 27 [knot/s] 44 [m/s] ; Max. sea state Heights 2.5 [m]; Max. surface current 2 $[\mathrm{knots} / \mathrm{s}] \sim 1[\mathrm{~m} / \mathrm{s}]$.

\section{B. LNG regasification process}

The floating storage and regaseification unit (FSRU) is now the first floating LNG regasification terminal based on conversion of an existing LNG carrier. The FSRU must receive LNG from offloading LNG carriers, and the onboard regasification system will provide gas send-out through flexible risers and pipeline to shore. The FSRU will be 
designed in compliance with DNV class rules and relevant international standards (Figure 1) [3], [4].

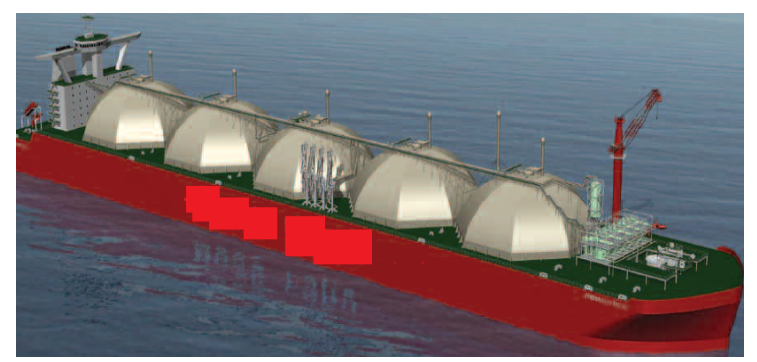

Fig. 1. Floating storage and regaseification unit -FSRU

LNG is sent from the tanks to the regasification skid fwd. The regasification skid essentially comprises booster pumps and vaporizers. The booster pumps will increase the pressure to about 90 [bar], before the high pressure LNG is vaporized, after which the gas passes a fiscal metering unit and is sent to the sub sea pipeline via the gas swivel and flexible risers. The regasification system shall have the following key design data: maximum gas send-out pressure- 85 [bar]; maximum gas send-out flow-240 [tonnes/h]; gas send-out temperature (min)$0\left[{ }^{\circ} \mathrm{C}\right]$ (Figure 2) [4].

The FSRU will be permanently moored approximately 600 [m] from port side and crew facilities [5].

The regasification equipment is arranged in parallel trains, assembled as separate modules, or the whole plant can be built in one module to fit to the available space. Each train consists of one or two LNG booster pumps and one shell and tube heat exchanger.

The booster pumps are fed by a common LNG buffer tank. The regasification system can be designed for open or closed loop operation, and the heating medium for LNG vaporization can either be sea water or steam [6]. The system can be designed to match any requirements to flow and pressure.

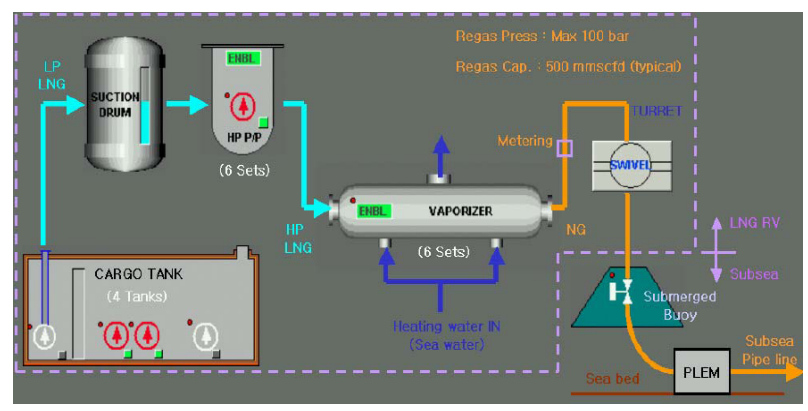

Fig. 2. The regasification process

The PT - Oman LNG diagram for thermodynamics of regaseification [1] is presented in the Figure 3:

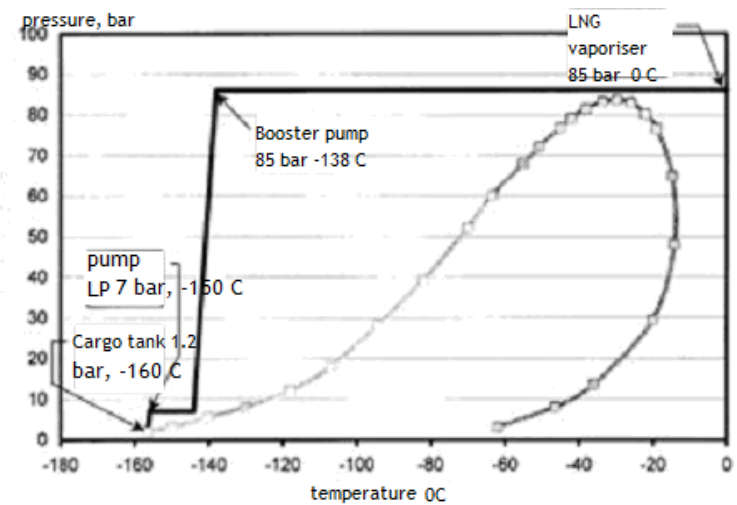

Fig. 3. The PT-Oman LNG diagram

The equipments of regasification process are presented in Figure 4 [6]:

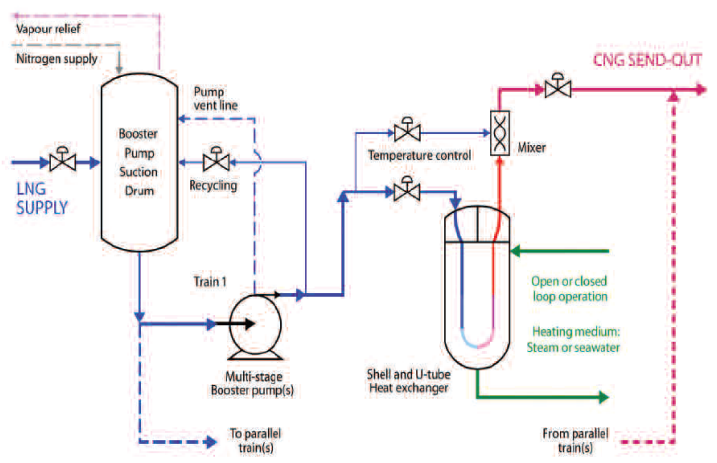

Fig. 4. The equipments of regasification process of LNG

\section{Regaseification facilities equipments}

The parameters of LNG storage as FSRU are: a) Cargo tank operating pressure (vapour pressure)-normal: 0.2 - 0.5 [bar]; SRV set point: 0.7 [bar] ; b) Hold Space pressurepressure set point relative to atmosphere is unchanged; hold space pressure set point relative to cargo tank pressure is unchanged; c) In-tank Pump configuration -cargo Tank 1, 2 and 3 with one new $500\left[\mathrm{~m}^{3} / \mathrm{h}\right]$ LNG transfer pump installed inplace of one of the existing LNG cargo transfer pumps;no change to pumps in Cargo Tank 4 and 5 .

The process of liquefying the natural gas involves compression and cooling of the gas to cryogenic temperatures (e.g. $-160^{\circ}$ Celsius). Prior to liquefaction the gas is first treated to remove contaminants, such as carbon dioxide, water and sulphur to avoid them freezing and damaging equipment when the gas is cooled. At this destination, the LNG is offloaded to special tanks onshore (Figure 5) [6], before it is either transported by road or rail on LNG carrying vehicles or revaporized and transported by e.g. pipelines. In many instances more advantageous to revaporize the natural gas aboard the seagoing carrier before the gas is off-loaded into onshore pipelines. LNG is sent from the tanks to the regasification skid situated forward. The regasification skid 
essentially comprises booster pumps and steam heated vaporizers.

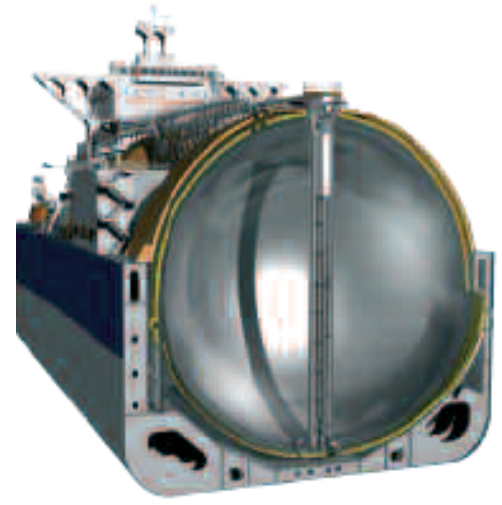

Fig. 5. LNG storage as FSRU

The regasification facilities for tank pump are: a) Purpose: supply of LNG to the booster pump suction drum via a new independent liquid header. b) Location: replaces one cargo pump in tanks 1, 2 and 3. c) Redundancy: 3 x 50\%, but existing cargo pumps may also be used. d) Rated Flow $: 500\left[\mathrm{~m}^{3}\right]$; e) Rated head: $150[\mathrm{~m}]$.

The regasification facilities for booster pumps suction drum are: a) Purpose:acts as a buffer volume during start-up, unexpected shut downs and capacity changes heat sink for the booster pumps during start-up. b) Location: on fwd deck, stbd of regas modules. c) Technical Data:volume $14\left[\mathrm{~m}^{3}\right]$, design pressure 10 [bar](Figure 6)[6,7].

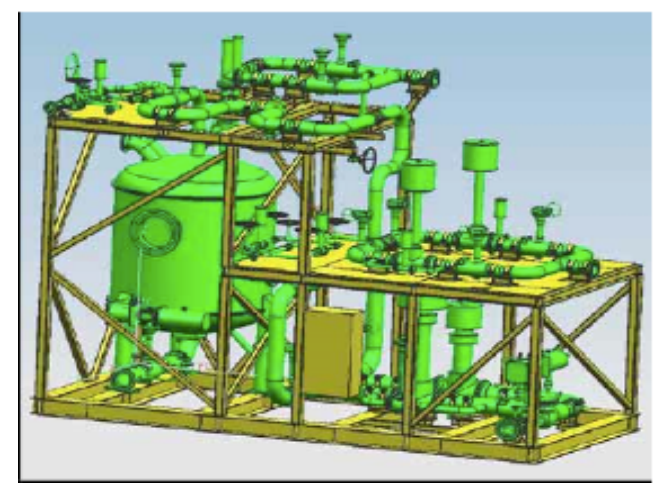

Fig. 6. The booster pumps suction drum

The regasification vaporisers most commonly used are: vaporizers in the system (VDS), Fig. 7 (a), (b)); combustion vaporizers submersible saw (VCS), Fig. 7 (c)).

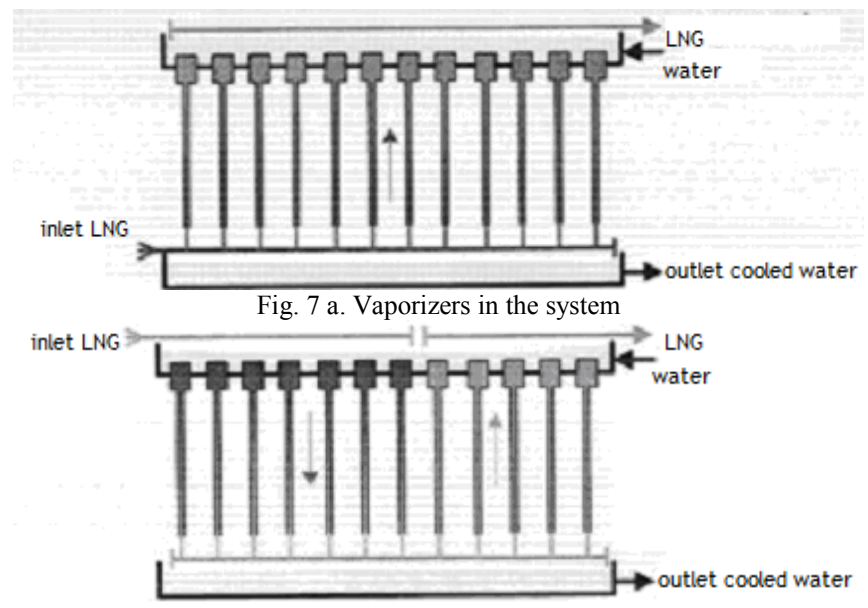

Fig. 7 b . Vaporizers in the system

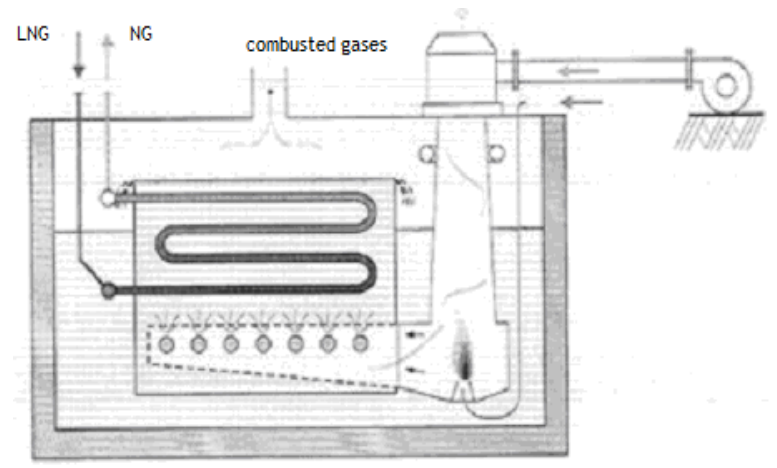

Fig. 7 c. Combustion vaporizers submersible saw

The following equipment is essential for each of the 3 regasification trains (Figure 8)[7,8]:2x50\% Booster pumps; 1 off LNG vaporizer,printed circuit heat exchanger -propane, LNG heated from $(-160)^{0} \mathrm{C}$ to approx $(-15)^{0} \mathrm{C} ; 2 \times 100 \%$ trim heaters (Figure 9)[7,8], shell / tube -sea water; propane loop: 1x propane tank, 1x propane circulation pump, 2x Propane evaporators, semi welded titanium plates.

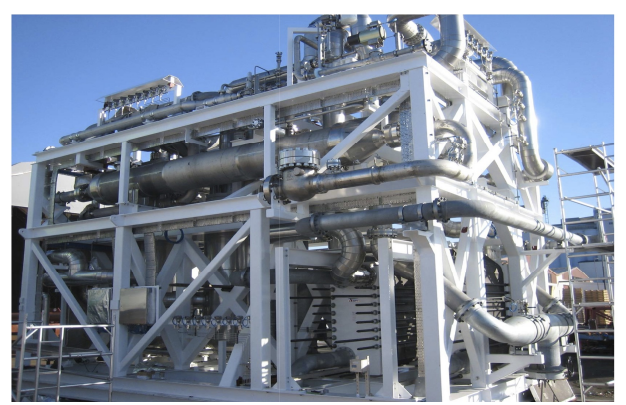

Fig. 8. Regasification trains 


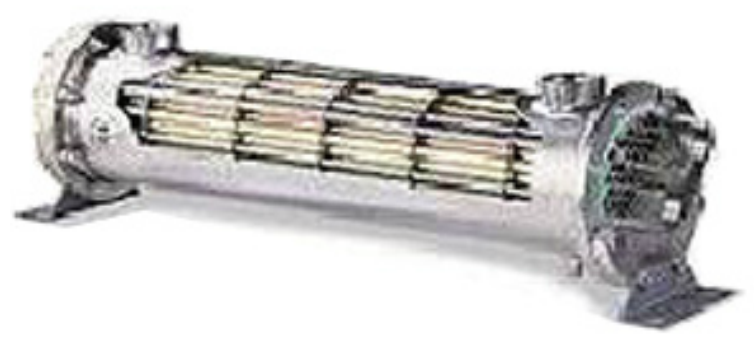

Fig. 9. Trim heater, shell/tube

III. THE MODELLING OF FLOW THROUGH A MULTITUBULAR IN SHELL COUNTER CURRENT HEAT EXCHANGER

Before we begin to modeling the flow, we must made some assumptions: 1) we have two and both are single-phase fluids and incompressible for a counter current heat exchanger in mantel; the density is constant and there is no accumulation of mass, $\mathrm{dm} / \mathrm{dt}=\mathrm{a}, 2$ ) the fluid space is considered independent variables extratubular $\mathrm{T}_{\sin }$ and $\mathrm{m}_{\mathrm{s}}$ for a number of nodes $\mathrm{N} ; 3$ ) metal pipe has a high thermal conductivity, so that axial temperature gradients are small and shape energy accumulation and convective heat transfer for average values of heat transfer coefficients; 4) for fluid pipes, $\mathrm{T}_{\text {tin }}$ and $\mathrm{m}_{\mathrm{t}}$ are independent variables, and $n$ is the number of nodes, flow occurs in the direction of increasing the number of nodes and node entry in the node's previous output.

We must build source files and files of results follows: source files for writing geometrical parameters, construction and material, to write the values used in the heat transfer coefficients, resulting files to calculate the geometric characteristics and heat transfer coefficients for $\mathrm{N}$ and $\mathrm{S}$ tube sections. The model is presented in Figure 12.

The inputs data are: dimensions for metal pipes (Figure 12 a) and tubular fluid(water parallelipiped)(Fig.12 b). Horizontal pipe $=10[\mathrm{~m}]$; (the two); Vertical pipe $=5[\mathrm{~m}]$; (nine); Water circulating through the parallelepiped-dimensions $10 \times 2 \times 1$ [m].

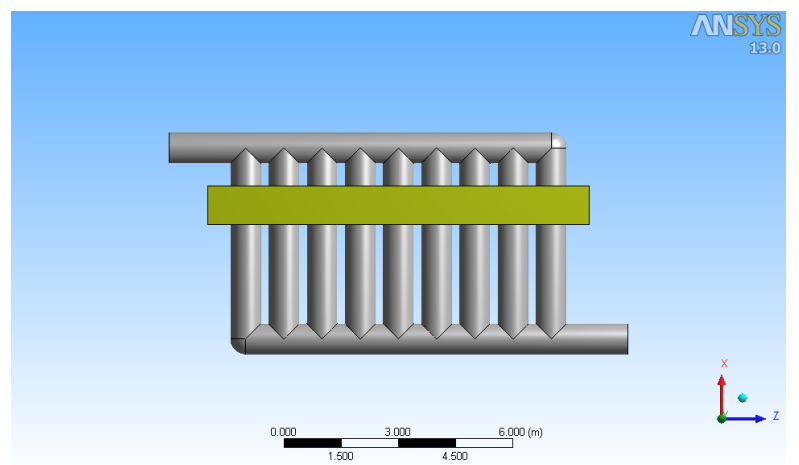

Fig.12a. The geometry of study for metal pipes and fluid(side)

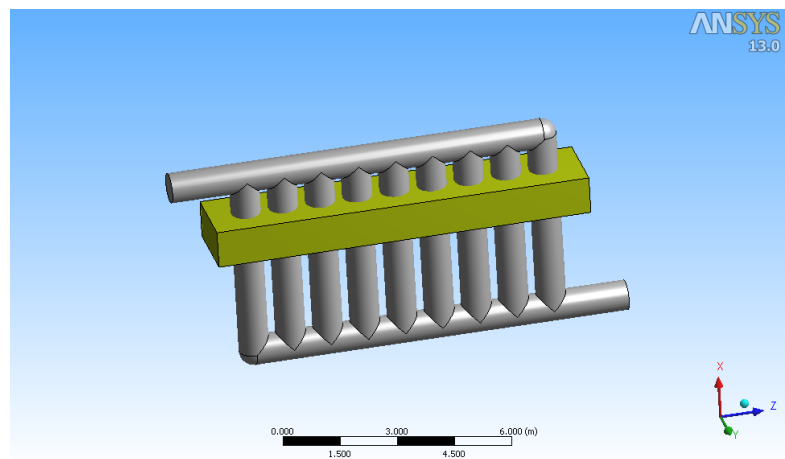

Fig.12b. The geometry of study for metal pipes and fluid (rotated)

Mesh network: number of elements 123744 of which tetrahedrons 112044 Hexahedron and 11 700(Figure 13). More presents 38544 knots.

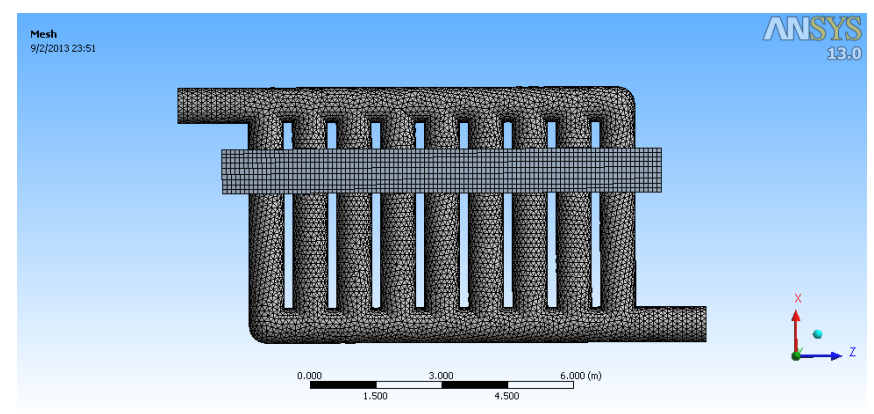

Fig. 13. Mesh network

Boundary conditions: water enters with a speed of $5[\mathrm{~m} / \mathrm{s}]$ at a temperature of $303[\mathrm{~K}]$ and comes out at atmospheric pressure at a temperature of $278[\mathrm{~K}]$. LNG enters with a speed of $2[\mathrm{~m} / \mathrm{s}]$ at a temperature of $113[\mathrm{~K}]$ and comes out at an atmospheric pressure at a temperature of 278 [K].

Turbulent model used k- $\varepsilon$.

\section{A. Equations}

We used for flow the equations of Navier-Stokes for gas and liquids. For turbulent model k-epsilon: we used the equation for turbulent kinetic energy $\mathrm{k}$ (1), disipation epsilon (2) and the energy equation (3):

$$
\begin{aligned}
& \frac{\partial}{\partial t}\left(\rho_{m} k\right)+\nabla \cdot\left(\rho_{m} \bar{v}_{m} k\right)= \\
& \quad=\nabla \cdot\left(\frac{\mu_{t, m}}{\sigma_{k}} \nabla k\right)+G_{k, m}-\rho_{m} \varepsilon \\
& \frac{\partial}{\partial t}\left(\rho_{m} \varepsilon\right)+\nabla \cdot\left(\rho_{m} \bar{v}_{m} \varepsilon\right)= \\
& =\nabla \cdot\left(\frac{\mu_{t, m}}{\sigma_{\varepsilon}} \nabla \varepsilon\right)+\frac{\varepsilon}{k}\left(C_{l \varepsilon} G_{k, m}-C_{2 \varepsilon} \rho \varepsilon\right)
\end{aligned}
$$




$$
\begin{aligned}
& \frac{\partial}{\partial t}(\rho E)+\nabla \cdot(\bar{v}(\rho E+p))= \\
& =\nabla \cdot\left(k_{\text {eff }} \nabla T-\Sigma_{j} h_{j} \bar{J}_{j}+\left(\bar{\tau}_{\text {eff }} \bar{v}\right)\right)+S_{h}
\end{aligned}
$$

where:

$$
\begin{gathered}
\rho_{m}=\sum_{i=1}^{N} \alpha_{i} \rho_{i}, \\
\bar{v}_{m}=\frac{\sum_{i=1}^{N} \alpha_{i} \rho_{i} \bar{v}_{i}}{\sum_{i=1}^{N} \alpha_{i} \rho_{i}}, \\
\mu_{t, m}=\rho_{m} C_{\mu} \frac{k^{2}}{\varepsilon}, \\
G_{k, m}=\mu_{t, m}\left(\nabla \bar{v}_{m}+\left(\nabla \bar{v}_{m}\right)^{T}\right): \nabla \bar{v}_{m},
\end{gathered}
$$

$\mathrm{k}_{\text {eff }}$ is effective conductivity; $\mathrm{J}_{\mathrm{j}}$ fluid diffusion flux $\mathrm{j} ; \mathrm{S}_{\mathrm{h}}$ heat due to chemical reaction. In the equation (3) we have:

$$
E=h-\frac{p}{\rho}+\frac{v^{2}}{2}
$$

$\mathrm{h}$ - enthalpy; for ideal fluids (9) and for real fluid (10)

$$
\begin{aligned}
& h=\sum_{j} Y_{j} h_{j} \\
& h=\Sigma_{j} Y_{j} h_{j}+\frac{p}{\rho} \\
& h_{j}=\int_{T_{r e f}}^{T} c_{p, j} d T
\end{aligned}
$$

\section{B. Results}

We have the graphic interpretation of the simulation results for the velocity (Figure 14), the pressure (Figure 15), the temperature (Figure 16) :

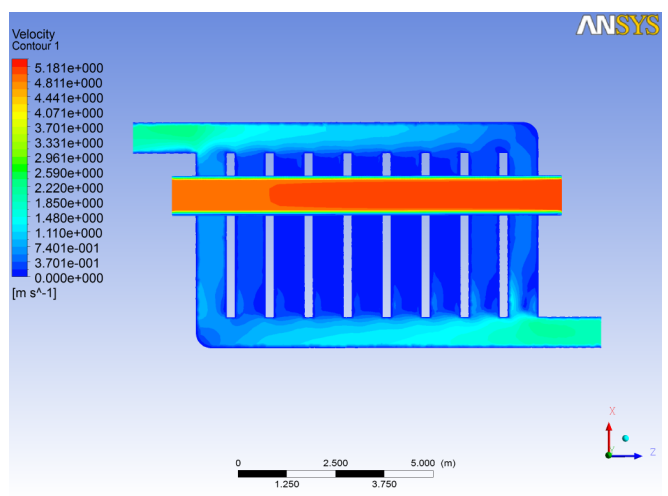

Fig. 14. The velocity

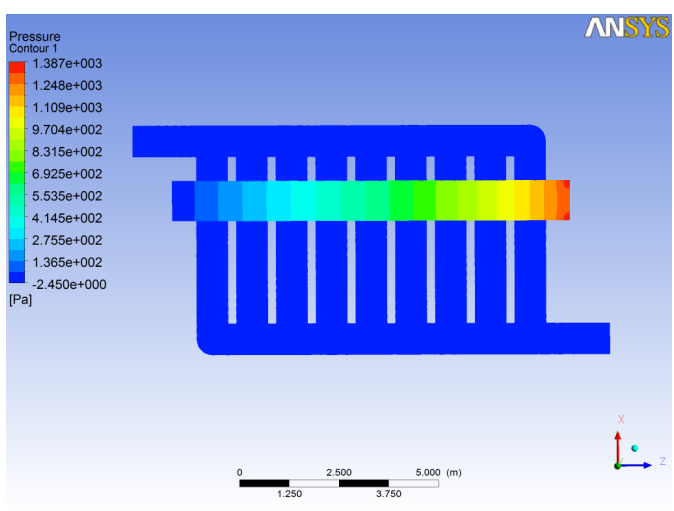

Fig. 15. The pressure

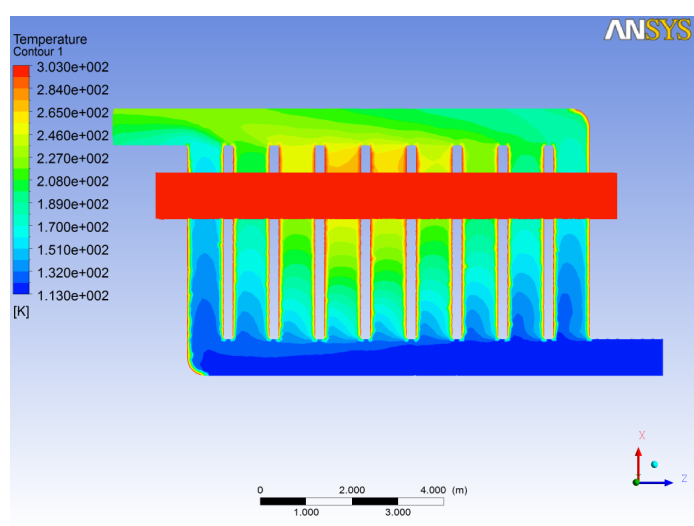

Fig. 16. The temperature.

\section{CONCLUSIONS}

The program is run for didactic use and no research as no exchange of heat through the walls of the LNG and water conditions imposed involves thermal radiation $\left[\mathrm{W} / \mathrm{m}^{3}\right]$ amount of which requires a separate program. We propose to another paperwork, for other conditions imposed (thermal radiation, porosity, etc.) to simulate through art, the flow of water through the pipe. The inlet temperatures and flow rates were used can used to obtain parameters by calculation of the operating point in steady flow.

\section{REFERENCES}

[1] Sagau, M., LNG import facility consisting of existing lng moss type vessel into floating terminal with regasification unit, Journal of Sustainable Energy, vol.4, no. 1-2, Romania, Oradea, May 2013, [Conference of Energy Engineering, CEE 2013,vol.4, no.1-2, p.206, 2013].

[2] Balan, M., et oth., Refrigeration plants, pp.66-68, pp.73-76, Todesco Publishing, 2000

[3] Hans Y.S. H., JungHan L.,YongSoo K., "Design Development of FSRU from LNG Carrier and FPSO Construction Experiences", OTC 14098, Offshore Technology Conference, 2002

[4] Vessel, IEEE Conference in Systems, 2009

[5] Hochung, K., JungHan, L., Design and construction of LNG regasification vessel, Proceedings of Gastech 2005, Spain, pp. 3-12.

[6] Groves, T., "Terminal LNG tank management system promotes storage safety", World Refining, May 2001,Vol.11, Iss. 4,pp.46-48.

[7] GOLAR FREEZE FSRU PROJECT MOSS MARITIME brochure Floating offshore LNG terminal, pdf, pp 4-6., 2012.

[8] Zellouf, Y., Portannier, B., First step in optimizing LNG storages for offshore terminals, Journal of Natural Gas Science and Engineering, Volume 3, Issue 5, pp. 582-590, 2011.

\section{Creative Commons Attribution License 4.0} (Attribution 4.0 International, CC BY 4.0)

This article is published under the terms of the Creative Commons Attribution License 4.0

https://creativecommons.org/licenses/by/4.0/deed.en_US 